Erratum

\title{
Exploring the Geography of Corporate Philanthropic Disaster Response: A Study of Fortune Global 500 Firms
}

\author{
Alan Muller \\ Gail Whiteman
}

\section{Erratum to: Journal of Business Ethics DOI 10.1007/s10551-008-9710-7}

During the proof procedure of this article, the authors overlooked a mistake in Table IV. The correct table is printed below.

TABLE IV

General Linear Model of donation values

\begin{tabular}{|c|c|c|c|c|c|}
\hline Source & Type III SS & df & Mean Square & $F$ & Sig. \\
\hline Corrected model & 392.938(a) & 12 & 32.745 & 20.209 & 0.000 \\
\hline Intercept & 62.079 & 1 & 62.079 & 38.313 & 0.000 \\
\hline Region & 51.094 & 2 & 25.547 & 15.767 & 0.000 \\
\hline Disaster & 70.466 & 2 & 35.233 & 21.745 & 0.000 \\
\hline Region $\times$ disaster & 51.947 & 4 & 12.987 & 8.015 & 0.000 \\
\hline Presence & 9.959 & 1 & 9.959 & 6.146 & 0.013 \\
\hline Region $\times$ presence & 1.762 & 2 & 0.881 & 0.544 & 0.581 \\
\hline Size & 157.823 & 1 & 157.823 & 97.404 & 0.000 \\
\hline Error & 837.690 & 517 & 1.620 & & \\
\hline Total & 99057.021 & 530 & & & \\
\hline Corrected total & 1230.628 & 529 & & & \\
\hline$R^{2}$ (adj.) & 0.303 & & & & \\
\hline
\end{tabular}

Alan Muller

Department of Strategy \& Marketing, University of Amsterdam Business School, Roetersstraat 11, 1018 WB Amsterdam, The Netherlands E-mail:amuller@uva.nl
Gail Whiteman Department of Business-Society Management, Erasmus University Rotterdam, Burg. Oudlaan 50, 3062 PA Rotterdam, The Netherlands

The online version of the original article can be found under doi:10.1007/s10551-008-9710-7. 